\title{
An investigation into sleep patterns and the effect of time of day on performance in youth swimmers
}

Marie Clare Grant and Jonathan Glen

This is an Accepted Manuscript of an article published by Taylor \& Francis in Biological Rhythm Research on 15th January 2018, available online:

wwww.tandfonline.com/10.1080/09291016.2018.1424774 


\section{An investigation into sleep patterns and the effect of time of day on performance in youth swimmers.}

Dr. Marie Clare Grant ${ }^{\mathrm{a}}$ and Jonathan Glen ${ }^{\mathrm{b}}$

${ }^{a}$ Division of Sport and Exercise Sciences, Abertay University, Dundee, United

Kingdom; ${ }^{b}$ Dundee Academy of Sport, Abertay University, Dundee, United Kingdom

*Corresponding author: Marie Clare Grant; marieclare.grant@abertay.ac.uk

(Received 13 December 2017; final version received 16 December 2017)

\section{Acknowledgements}

The authors would like to thank the coaches, swimmers and their parents for their participation in the study.

\section{Funding}

This research did not receive any specific grant from funding agencies in the public, commercial, or not-for-profit sectors. However, the researchers were supported by the Dundee Academy of Sport, Abertay University.

\section{Word Count}

4378 (excluding abstract, acknowledgements, funding and references) 


\title{
An investigation into sleep patterns and the effect of time of day on performance in youth swimmers.
}

\begin{abstract}
The purpose of this study was to investigate sleep patterns in competitive youth swimmers and to establish any time-of-day effect on physiological and psychological variables linked to swimming performance. Twelve swimmers $(14.8 \pm 2.1$ years $)$ underwent physiological and psychological tests in morning and evening and completed sleep diaries over a 2-week period. There was a nonsignificant effect between morning and evening swimming performance for $800 \mathrm{~m}(\mathrm{p}=0.068)$ and $50 \mathrm{~m}(\mathrm{p}=0.306)$. Handgrip strength was significantly greater in evening $(\mathrm{p}=0.007)$, back and leg strength were significantly greater in morning $(p=0.013)$. There was no time-of-day effect for jump height $(p=0.756)$. The profile of mood states indicated significantly higher anger $(p=0.012)$ and vigour $(\mathrm{p}=0.000)$ in the morning. Swimming performance was not significantly affected by time of day; however, physiological variables showed varied results. Multiple factors could be influencing results including training time and mood state so should be monitored closely by coaches.
\end{abstract}

Keywords: swimming, performance, sleep, time-of-day, habitual training, strength

\section{Introduction}

Sleep is essential for human health and is particularly important for an athlete's recovery due to its physiological and psychological restorative effects (Leeder, Glaister, Pizzoferro, Dawson and Pedlar, 2012) The general daily recommendation for sleep is 7-8 hours (Marshall and Turner, 2016) with less than 6 hours per day linked disturbances in a number of variables (Sargent, Halson and Roach, 2014) including glucose metabolism, appetite regulation (Spiegel, Tasali, Peney and Cauter, 2004), cognitive capacity (Axelsson et al., 2008) and immune function (Vgontzas et al., 2004). Furthermore, athletes who have had insufficient sleep tend to report higher levels of exertion and a poorer mood state which may influence their motivation to train and perform effectively (Reilly and Edwards, 2007). 
Sleep deprivation is a common concern in sports such as swimming where athletes typically train for prolonged periods, both in the morning and evening, in an attempt to maximise training gains (Forndran, Lastella, Roach, Halson and Sargent, 2012). In relation to world class swimmers, it has been found that early morning training has a significant impact on sleep duration (Sargent et al., 2014). Prior to morning training, the athletes slept on average 5.4 hours per night which is well below recommend sleep duration and linked to a poorer mood state and higher feelings of exertion during training (Fullagar et al., 2015; Sargent et al., 2014). Napping during the day has been recognised as an effective tool for recovery between sessions (Halson, 2014) with evidence to suggest that a 30 minute nap can improve sprint performance and alertness whilst reducing sleepiness (Waterhouse, Atkinson, Edwards and Reilly, 2007). Although this may be a practical solution for elite athletes, younger highly trained swimmers are often required to complete similar training schedules whilst attending school between sessions making napping near impossible.

In addition to sleep duration, there is also evidence to suggest that exercise performance may be affected by the time-of-day with previous research suggesting that physical performance in late afternoon/early evening is improved when compared with the same task carried out in the morning (Souissi et al., 2008). These variations in performance have been linked to the circadian rhythmicity of physiological and behavioural processes within the human body which follow a 24 hour cycle (Gubin et al., 2017). The synchronisation of these variables to a precise 24 hour period is regulated by signals known as Zeitgebers. The main Zeitgeber is the light/dark cycle whereby the internal body clock, which consists of paired suprachiastmatic nuclei at the base of the hypothalamus, is adjusted to the solar day (Gubin et al., 2017). Neural pathways from the retina to the hypothalamus respond to light (by suppressing receptors for melatonin) 
and dark (by stimulating receptors for melatonin) which can impact physiological variables such as core temperature and blood pressure which in turn may influence physical performance (Atkinson, Todd, Reilly and Waterhouse, 2005; Reilly et al., 2007) However, exogenous factors such as environmental temperature, activity, social interaction, timing of meals and sense of occasion can also have an impact upon the diurnal variation of these physiological and biochemical variables (Edwards, Reilly and Waterhouse, 2009; Thun, Bjorvatn, Flo, Harris and Pallesen, 2015) and therefore may have an a concomitant effect on physical performance (Reilly and Waterhouse, 2009). Improved physical performance in the evening has been classically linked to an increased core temperature improving factors such as metabolic reactions, nerve conduction velocity (Ferrario, Tredici and Crespi, 1980; Shephard, 1984) and joint suppleness (Fathallah, Marras and Wright, 1995). However, there is more recent evidence to suggest that the time-of-day may affect muscle contractile properties due to intracellular variations within skeletal muscle. These variations include changes in inorganic phosphate $(\mathrm{Pi})$ concentration and calcium $\left(\mathrm{Ca}^{2+}\right)$ release from the sarcoplasmic reticulum (Abedelmalek et al., 2013; Chtourou et al., 2012).

The concept of greater physical performance in the evening is evident in both short duration, high intensity exercise and longer duration exercise. For example, mean and peak power output during a 30s Wingate test (Souissi et al., 2007) and mean power output during a 60s Wingate test (Lericollais, Gauthier, Bessot, Sesboue and Davenne, 2006) have been found to be significantly higher at 18:00 than at 06:00. Longer duration endurance performance, demonstrated by an increase in time to exhaustion, has also been found to be greater in the evening (Bessot et al., 2006; Hill and Rowell, 1996) However, there is also evidence to the contrary with no time-of-day effect found during a 30s Wingate test (Reilly and Down, 1992) or an arm isokinetic test on a swim bench 
(Reilly and Marshall, 1991). Furthermore, a number of studies have failed to show a correlation between time-of-day and markers of aerobic performance, including $\mathrm{VO}_{2 \text { peak }}$ (Bessot et al., 2011) and time to exhaustion (Hill, Cureton, Collins and Grisham, 1988). It has been suggested that lack of diurnal variation in performance may be related factors such as chronotype, habitual training time and polymorphisms within clock genes may influence any diurnal variation related to sporting performance (Rae, Stephenson and Roden, 2015).

Psychological factors may also be affected by the time-of-day, which could have concurrent impact on physical performance. Particularly relevant to sporting performance is mood state (Beedie, Terry and Lane, 2000) which can play a key role in adhering to training and competition (Lemyre, Roberts and Stray-Gundersen, 2007). A poorer mood state at a particular time-of-day may adversely affect performance outcomes.

Any diurnal variation in physiological and psychological variables and/or sleep deprivation can potentially have consequences for swimmers both during both training and in competition. Therefore, the purpose of this study is to investigate sleep patterns in highly trained youth swimmers and to establish if there is any effect of the time-ofday on swimming performance, other physical tasks and mood state. It was hypothesised that all performance in all physical tests would improve in the evening compared to the morning, some of which may be linked to variation in mood state.

\section{Methodology}

\section{Experimental overview}

This investigation used a cross over design where all participants completed all trials. Within-subject comparisons were made in all measured variables to assess the time of day effect on performance and mood state. 


\section{Participants}

Twelve competitive youth swimmers from a local community-swimming club volunteered to participate in the study (Table 1). All swimmers were regional level swimmers, trained for a minimum of eight hours per week in the pool, and reported no injuries or illness prior to the investigation. The study was approved by the university ethical committee and all participants and parents of those under the age of sixteen signed an informed consent form and completed a medical history questionnaire. Participants were instructed to maintain their normal diet during the days leading up to, and on the days of testing. Food was not consumed during testing and water was available ad libitum.

[Table 1 near here]

\section{Procedures}

All participants completed two trials in the morning (05:30-06:30) and two trials in the evening (17:30-18:30). Within each session, handgrip strength, back and leg strength, countermovement jump height (CMJ) and swimming performance $(50 \mathrm{~m}$ or $800 \mathrm{~m}$ frontcrawl) were measured. Prior to the physical tests, all participants also completed a Profile of Mood States (POMs). Each testing session was separated by at least 36 hours. All participants completed two familiarisation sessions prior to the trials. During these sessions, height $(\mathrm{cm})$ and body mass $(\mathrm{kg})$ were recorded and participants completed a Horne-Östberg morningness-eveningness personality questionnaire ${ }^{35}$ and were instructed on how to complete the sleep diary ${ }^{36}$. The sleep diary was kept for a duration

of 14 days and participants were asked to maintain the habitual sleeping habits throughout.

\section{Countermovement jump (CMJ)}

The CMJ test was conducted on a jump mat (The Just Jump mat, Probotics, Huntsville, AL) and was used to measure vertical jump height $(\mathrm{cm})^{37,38}$. Participants started from an 
upright standing position with their legs fully extended and feet shoulder width apart. An initial downward movement to a self-selected depth was made by flexing the knees and hips while swinging their arms back and then immediately extending the knees and hips again to jump vertically as high as possible. Three maximum vertical jumps were performed with one-minute rest between trials. As a measure of maximal performance, the best result was retained for analysis. ${ }^{37,39}$

\section{Handgrip strength}

For each participant the handgrip was adjusted to a position which was comfortable and the middle knuckles were resting on the grip bar of the digital handgrip dynamometer (Takei TKK 5401, Takei, Japan). Participants stood with feet shoulder width apart whilst holding the dynamometer at shoulder height with the elbow extended. ${ }^{40}$ They were instructed to squeeze the grip bar as hard as possible for at least two seconds whilst gradually bringing their arm back towards their side. Participants performed three maximum attempts with their dominant hand, with one minute recovery between trials. As a measure of maximal performance, the best result was retained for analysis. ${ }^{37,39}$

\section{Leg and back strength}

Participants stood on the digital leg and back dynamometer (Takei TKK 5402, Takei, Japan) with the chain adjusted so that their arms were aligned straight down from their shoulders and knees were flexed at approximately $115^{\circ} .{ }^{41}$ Participants were instructed to keep their back straight and then pull the chain up as hard as possible whilst keeping their arms straight. Three maximum trials were performed, with one-minute recovery between trials. As a measure of maximal performance, the best result was retained for analysis. 37,39

Pool tests 
Prior to the pool tests all participants completed a standardised warm up $(800 \mathrm{~m}$ frontcrawl, R30s; 4x100m choice stroke, R15s; 8x50m frontcrawl (alternating kick and pull, increasing effort), R10s; 4x25m frontcrawl (maximal effort), R60s). In a 25m pool, from a track start, on starting blocks, time to complete a distance of either $50 \mathrm{~m}$ or $800 \mathrm{~m}$ was recorded. All participants completed each distance twice, once in the morning and once in the evening during the times previously outlined. Each trial was performed under simulated race conditions with a block start, tumble turns and instructions to produce a maximal effort. All tests were conducted in the $25 \mathrm{~m}$ pool with experienced coaches recording times using a split-timing stopwatch. The use of stopwatches by experienced coaches has been found to have acceptable levels of precision ${ }^{42}$ and is similar to procedures used by Weston et al. ${ }^{43}$

\section{Profile of mood states (POMs)}

Prior to each testing session, mood state was assessed using the POMs questionnaire ${ }^{44}$. The POMs questionnaire provided a subjective measure of mood state through assessing tension, depression, anger, vigour, fatigue and confusion. Total mood disturbance was calculated by subtracting the score for vigour (positive mood state measurement) from the total score of tension, depression, anger, fatigue and confusion (negative mood state measurements). There were a total of 65 items that were rated on a scale of 0 (not at all) to 4 (extremely).

\section{Morning-eveningness questionnaire (MEQ)}

All participants competed a $\mathrm{MEQ}^{35}$ to assess their chronotype. There was a total of 19 questions with 4 or 5 response options for each question. This was completed during the first familiarisation session.

Sleep diary 
Participants completed a daily sleep diary for a total duration of 14 days that encompassed all trials in the investigation. The diary was adapted from Morgan et al. ${ }^{45}$ and asked a total of 9 questions. The questions asked were as follows. At what time you go to bed last night?; 2. After settling down, how long did it take you to fall asleep?; 3 . After falling asleep, about how many times did you wake up in the night?; 4. After falling asleep, for how long were awake during the night in total?; 5. At what time did you finally wake up?; 6. At what time did you get up?; 7. How long did you spend in bed last night?; 8. How would you rate quality of you sleep last night?; 9. Did you have a nap today? If so how long did it last? Participants were also asked to rate their sleep quality each night on a scale of 1 to 5 ( $1=$ very poor; $5=$ very good $)$.

\section{Statistical analysis}

Data was statistically analysed using SPSS (Version 22) (IBM, Armonk, NY, USA). Normality of data distribution was tested by a Shapiro-Wilk's test. Differences between morning and evening test values were determined using a paired t-test or a Wilcoxon matched pairs tests for non-parametric data (POMs outcomes for depression, anger, fatigue and confusion). Effect size statistics (ES) for selected $t$ - and $F$-ratios were also established. These calculations were based on Cohen's $(d)$ classification of a small $(0.2$ $\leq d<0.5)$, moderate $(0.5<d<0.8)$ and large $(d \geq 0.8) \mathrm{ES}^{46}$. Significance was set $a$ priori at $p<0.05$. All data are presented as mean \pm standard deviation (SD).

A total of 4 participants were unable to complete the $800 \mathrm{~m}$ trials in one of the two sessions and therefore were removed from this section of the analysis.

\section{Results}

\section{Swimming performance}

There was a small non-significant effect between morning (AM) and evening (PM) swimming performance for both 800m (s) (AM: 638.7 \pm 51.4 , PM: $627.0 \pm 48.7, p=$ 
0.068; $\mathrm{ES}=-0.33)$ and 50m (s) (AM: $30.4 \pm 1.3, \mathrm{PM}: 30.2 \pm 1.2, p=0.306 ; \mathrm{ES}=-0.26)$ where performance tended to be greater in the evening. Figures 1 and 2 demonstrate patterns of change for individual swimmers (Weisserber, Mills, Winham and Garovic, 2015).

\section{Physical parameters}

Handgrip strength was found to be significantly greater in the evening whereas back and leg strength was found to be significantly greater in the morning. There was no difference between morning and evening performance in CMJ. Table 2 displays the physiological parameters measured in morning and evening.

\section{Psychological parameters}

POMs data revealed that the swimmers had significantly higher levels of anger in the morning compared to the evening (AM: $3.9 \pm 3.5$, PM: $2.0 \pm 1.8, p=0.012$; $\mathrm{ES}=0.96$ ). Time-of-day had large effect on vigour which was also found to be significantly greater in the morning compared to evening $(\mathrm{AM}: 19.7 \pm 3.1, \mathrm{PM}: 11.5 \pm 3.5, p=0.000$; $\mathrm{ES}=$ 3.27). There was a medium, non-significant effect of time-of-day effect on tension (AM: $5.9 \pm 3.9, \mathrm{PM}: 4.7 \pm 2.4, p=0.159 ; \mathrm{ES}=0.54)$ and depression, (AM: $3.1 \pm 3.6$, PM: $1.8 \pm 3.5, p=0.286$; $\mathrm{ES}=0.53$ ). There were no significant differences found for fatigue (AM: $6.0 \pm 4.7, \mathrm{PM}: 5.6 \pm 3.9, p=0.479 ; \mathrm{ES}=0.15)$ or confusion (AM: $2.3 \pm$ 2.6, PM: $1.8 \pm 2.0, p=0.181 ; \mathrm{ES}=0.35$ ) between morning and evening. No differences were found in total mood disturbance (defined as vigour minus the total of all other variables) (AM: $-1.6 \pm 15.1, \mathrm{PM}:-3.9 \pm 7.2, p=0.388 ; \mathrm{ES}=0.27)$. Figure 3 displays the mean values for each of the POMs variables. It demonstrates an iceberg profile, typical of that found in athletes.

Chronotype 
The MEQ indicated that eight swimmers were 'intermediate type' and three swimmers were 'moderately morning type'. One questionnaire was incomplete and therefore excluded from any further analysis.

\section{Sleep duration and quality}

Over a 14 day period, the average sleep duration for the swimmers $(n=10)$ was $495.6 \pm$ 41.0 minutes (approx. 8.3 hours). This falls within the general recommendation of 7-9 hours of sleep with only one participant having a slightly lower average sleep duration of 6 hours 51 minutes (411.6 minutes). The average time the swimmers woke up over the two week period was $06: 24$, this ranged from $05: 12$ to $08: 04$ with the earlier time reflecting morning training and the later time being on a Sunday with no school or training to attend. The average time the swimmers went to sleep over the two week period was 21:46, this ranged from 21:24 to $22: 22$ with the later time again being on a Sunday where participants had slept to a later time in the morning (Figure 4). Sleep quality was measured on a scale of 1 (very poor) to 5 (very good) with a reported mean value of $4.0 \pm 0.5$. Two sleep diaries were incomplete and removed from the analysis.

\section{Discussion}

The purpose of the investigation was to assess the effect of time-of-day on both physiological and psychological variables and to determine sleep patterns in young competitive swimmers. The main findings to emerge from the study was that there was no significant time-of-day effect on swimming performance $(p>0.05)$ and that the swimmers in the present study slept, on average, for a duration of $>8$ hours per night therefore generally meeting the recommendations for daily sleep.

First, it is important to note that the lack of any significant time-of-day effect on swimming performance may be linked to fact that the swimmers in the present study trained regularly both in the morning and evening. Therefore, the effect of habitual 
training time on performance may have blunted any time-of-day effect linked to physical performance. This suggestion is supported by previous studies in swimmers where it was found that Masters swimmers performed better during their habitual training time. That is, the swimmers who habitually trained in the morning were faster in the morning than in the evening and vice versa. (Rae et al., 2015). Similarly, Ferchichi et al. (2016) investigated performance in college level swimmers and found that following an 8-week training programme at two different times of day there was a greater impact on performance at the time at which training took place. Furthermore, it can also be suggested that the lack of diurnal variation in performance may be linked to the extensive warm up completed prior to each swim test (Deschodt and Arsac, 2004). Active warm up protocols have been shown to minimise any differences in morning and evening performance possibly due to an increase in core temperature having a positive impact on morning performance (Souissi et al., 2010).

Although a number of studies support the common perception that short duration, high intensity performance is greater in the evening (e.g. Hill and Smith, 1991; Souissi et al., 2007), there is a degree of ambiguity in findings from previous investigations and therefore some evidence which supports the findings of the present investigation, in that time-of-day does not affect 50m swim performance. For example, the effect of time-ofday on a 30s Wingate test, which is approximately the same duration as a $50 \mathrm{~m}$ freestyle sprint, has been investigated by Reilly and Down (1992) who found a non-significant relationship between time-of-day and Wingate performance. The authors highlight that high intensity exercise performance requires a combination of motivation and psychological drive and suggest that this may partially explain why some studies have found a time-of-day effect in short duration high intensity activities (Reilly and Down, 1992). It can therefore be suggested that in the present study significantly higher levels 
of vigour in the morning $(p<0.05)$, alongside the effect of habitual training time, may have further masked the impact of any positive physiological changes in the evening (Beedie et al., 2000).

There is a scarcity of information available that is directly related to swimming performance, however, in contrast to the findings of the present study, Deschodt and Arsac (2004) found 50m swimming velocity to be higher in the evening compared to the morning and afternoon in university level swimmers. In agreement with previous suggestions, the authors outline that any time-of-day effect on performance may be able to be minimised through regular morning training and an extensive warm up procedure that can be particularly important during competition where swimming fast in morning heats is required to qualify for evening finals (Deschodt and Arsac' 2004)

Despite the suggestion from the current study, that time-of-day does not significantly impact swimming performance in swimmers who train habitually in the morning and evening, it should be highlighted, that there was an average improvement of $1.8 \%(11.7$ s) in $800 \mathrm{~m}$ evening performance. This equates to a distance of approximately 15 meters, which could clearly determine the outcome of a race. This is similar to the findings of Bessot et al., (2011) who found that in trained endurance cyclists there was no significant time-of-day effect on $\mathrm{VO}_{2 \max }$, maximum power or maximal aerobic power during a maximal aerobic test. However, all the afore-mentioned variables showed a slight improvement from morning (06:00) to evening performance (18:00). It is also worth noting that the chronotype of the swimmers was unlikely to be a major influencing factor, with eight of the swimmers being classed intermediate and two as moderately morning. This is similar to the profile of the University swimmers studied by Deschodt and Arsac (2004) and may reflect either a modification in chronotype through regular athletic activity in the morning or morning types being more drawn 
towards activity in the morning (Rae et al., 2015). However, it should be highlighted that chronotype is known to be somewhat variable until after adolescence (Brown, Neft and LaJambe, 2008).

Based on the conflicting evidence relating to the effects of time-of-day on performance it may be that simply comparing group data does not reveal the true implications for performance. For each swimmer individual times should be analysed by the coach to assess the true impact of the time-of-day.

As overall strength and power is known to be important for successful swimming performance (Bishop et al., 2013), CMJ, handgrip strength and back and leg strength were also assessed in the morning and evening. These measures of strength and power were utilised as they have been shown to be valid and reliable measures that can easily be conducted in the field (Castro-Piñero et al., 2009; Lubans et al., 2011). Handgrip strength was found to be significantly greater in the evening $(p<0.05)$ whereas leg and back strength was found to be significantly greater in the morning $(p<0.05)$. There was no time-of-day effect found for CMJ performance $(p>0.05)$.

Relatively few studies have investigated the influence of time-of-day on the aforementioned performance variables. In relation to handgrip strength, most findings are in agreement with the present study. For example, Souissi et al., (2010) investigated exercise performance in 10-11 year old boys and found handgrip strength to be significantly lower at 08:00 than at 14:00 and 18:00. Similarly, handgrip strength in university level footballers was found to peak in the evening (20:00) (Reilly et al., 2007). When EMG was used to investigate the effect of time-of-day on force production in adductor pollicis muscle it was suggested that the variations in isometric force were mainly attributable to peripheral changes linked to faster muscle contractile properties in the evening (18:00 vs. 07:00) (Martin, Carpentier, Guissard,van Hoecke 
and Duchateau, 1999). It is speculated that a greater force production in the evening (18:00) was due to changes in the process of skeletal muscle excitation-contraction (EC) coupling, for example, greater $\mathrm{Ca}^{2+}$ release form the sarcoplasmic reticulum and increased sensitivity of contractile proteins for $\mathrm{Ca}^{2+}$ (Martin et al., 1999). It therefore seems that handgrip performance of the swimmers was not affected by mood state as it has been found to be positively correlated with high levels of vigour and anger. Both these variables were both found to significantly higher in the morning in the present study, which may reflect familiarity with being physically active at a given time-of-day (Rae et al., 2015) and therefore be masking any performance differences.

Although most evidence indicates a trend towards jump performance being greater in the evening (e.g. Bernard et al., 1998; Chtourou et al., 2013), there are discrepancies in findings with some evidence in agreement with the findings of the current study, suggesting no time-of-day effect on jump performance (Brown et al., 2008; Reilly et al., 2007) Particularly relevant to the present study, in collegiate rowers who trained both in the morning and evening, there was no time-of-day effect on standing broad jump performance (Brown et al., 2008). This again highlights the possible influence of habitual training time blunting any time-of-day effect. It is also possible that familiarity of movement of the $\mathrm{CMJ}$ to swimmers may minimise any diurnal variation in jump performance (Rae et al., 2015). Swimmers regularly perform similar phases of movement to the CMJ where during starts and turns when contact is made with the wall there is extension of the hips, knees and ankles to generate speed away from the wall (Bishop et al., 2013; Potdevin et al., 2011). Therefore, a combination of habitual training time, familiar movement patterns and consequently well-developed motor skills may play a role in minimising any time-of-day effect linked to jump performance. 
Few studies have investigated back and leg strength using a dynamometer but as with other performance variables, there is a suggestion that performance is better in the evening (Coldwells, Atkinson and Reilly, 1994). It is possible that the greater back and leg strength in the morning found in the present study may be linked to the significantly higher levels of vigour and anger in the morning. In particular higher level of anger have been linked to increased peak force in the leg and back muscles (Davis, Woodman and Callow, 2010).

Based on the data collected via sleep diaries, it seems unlikely the swimmers in the present study were sleep deprived. On average, they slept for a duration of 8.3 hours (with sleep quality generally rated good-very good). This fits with the recommendation of 7-9 hours for psychological and physiological recovery (Thun et al., 2015). However, it should be noted that it has been suggested that athletes may need to sleep for a longer duration for optimal recovery from injury, intense training and competition (Thun et al., 2015). Furthermore, the adolescents in the present study follow a fairly consistent sleep pattern during weekdays and weekends (Figure 4). This is perhaps unusual for individuals within this age group where sleep at the weekend is often used to compensate for an accumulated weekday deficit (Short, Gradisar, Lack, Wright and Dohnt, 2013) and it may be that a structured training schedule helps young people achieve a more regular.

The main limitation within the present study is the self-reporting of sleep duration and quality. The use of activity monitors and/or electroencephalographic data would improve the validity of sleep data

It can be suggested that young highly trained swimmers who train habitually in the morning and evening are largely unaffected by the time-of-day. However, to ensure 
optimal performance in the morning and evening a suitable warmup protocol should be implemented prior to competition.

\section{Acknowledgements}

The authors would like to thank the coaches, swimmers and their parents for their participation in the study.

\section{Conflicts of Interest}

The authors report no conflicts of interest.

\section{Funding}

This research did not receive any specific grant from funding agencies in the public, commercial, or not-for-profit sectors. However, the researchers were supported by the Dundee Academy of Sport, Abertay University. 


\section{References}

Abedelmalek, S., Chtourou, H., Aloui, A., Aouichaoui, C., Souissi, N. and Tabka Z. (2013). Effect of time of day and partial sleep deprivation on plasma concentrations of IL-6 during a short-term maximal performance. European Journal of Applied Physiology, 13(1), 241-248.

Atkinson, G., Todd, C., Reilly, T. and Waterhouse, J. (2005). Diurnal variation in cycling performance: influence of warm-up. Journal of Sports Sciences, 23(3), 321-329. Axelsson. J., Kecklund, G., Akerstedt, T., Donofrio, P., Lekander, M. and Ingre, M. (2008). Sleepiness and performance in response to repeated sleep restriction and subsequent recovery during semi-laboratory conditions. Chronobiology International, $25,297-308$

Beedie, C. J., Terry, P. C. and Lane, A. M. (2000).The Profile of Mood States and athletic performance: Two meta-analyses. Journal of Applied Sports Psychology, 12(1), 49-68.

Bencke, J., Damsgaard, R., Saekmose, A., Jørgensen, P., Jørgensen, K. and Klausen, K. (2002). Anaerobic power and muscle strength characteristics of 11 years old elite and non-elite boys and girls from gymnastics, team handball, tennis and swimming. Scandinavian Journal of Medicine and Science in Sports, 12(3), 171-178. 
Bernard, T., Giacomoni, M., Gavarr, O., Seymat, M. and Falgairette, G. (1998).Timeof-day effects in maximal anaerobic leg exercise. European Journal of Applied Physiology and Occupational Physiology, 77, 133-138.

Bessot, N., Nicolas, A., Moussay, S., Gauthier, A., Sesboüé, B. and Davenne, D. (2006). The effect of pedal rate and time of day on the time to exhaustion from high-intensity exercise. Chronobiology International, 23(5), 1009-1024.

Bessot, N., Moussay, S., Dufour, B., Davenne, D., Sesboüé, B. and Gauthier, A. (2011). Time of day has no effect on maximal aerobic and peak power. Chronophysiology and Therapy, 1, 11-16.

Bishop, C., Cree, J., Read, P., Chavda, S., Edwards, M. and Turner, A. (2013). Strength and conditioning for sprint swimming. Strength and Conditioning Journal, 35(6), 1-6. Brown, F. M., Neft, E. E. and LaJambe, C. M. (2008). Collegiate rowing crew performance varies by morningness-eveningness. Journal of Strength and Conditioning Research, 22(6), 1894-1900.

Castro-Piñero, J., Chillon, P., Ortega, F. B., Montesinos, J. L., Sjöström, M. and Ruiz, J. R. (2009) Criterion-related validity of sit-and-reach and modified sit-and-reach test for estimating hamstring flexibility in children and adolescents aged 6-17 years. International Journal of Sports Medicine, 30(9), 658-662.

Chtourou, H., Chaouachi, A., Driss, T., Dogui, M., Behm, D. G., Chamari, K. and Souissi, N. (2012). The effect of training at the same time of day and tapering period on the diurnal variation of short exercise performances. Journal of Strength and Conditioning Research, 26(3), 697-708.

Chtourou, H., Aloui, A., Hammouda, O., Chaouachi, A., Chamari, K. and Souissi, N. (2013). Effect of static and dynamic stretching on the diurnal variations of jump performance in soccer players. PloS one, 8(8), e 70534. 
Cohen, J. (1988). Statistical power analysis for the behavioral sciences. (2nd ed.). Hillsdale, NJ: Lawrence Earlbaum Associates.

Coldwells, A., Atkinson, G. and Reilly, T. (1994). Sources of variation in back and leg dynamometry. Ergonomics, 37(1), 79-86.

Davis, P. A., Woodman, T. and Callow, N. (2010). Better out than in: The influence of anger regulation on physical performance. Personality and Individual Differences, $49(5), 457-460$.

Deschodt, V. J. and Arsac, L. M. (2004). Morning vs. evening maximal cycle power and technical swimming ability. Journal of Strength and Conditioning Research, 18(1), $149-154$

Edwards, B. J., Reilly, T. and Waterhouse, J. (2009). Zeitgeber-effects of exercise on human circadian rhythms: what are alternative approaches to investigating the existence of a phase-response curve to exercise? Biological Rhythm Research, 40, 53-69.

Fathallah, F. A., Marras, W. S. and Wright, P. L. (1995). Diurnal variation in trunk kinematics during a typical work shift. Journal of Spinal Disorders, 8(1), 20-25.

Ferchichi, S., Taktak, Y., Taktak, H., Chtourou, H., Zarrouk, F., Tabka, Z. and Souissi, N. (2016). The effect of training at the same time-of-day on the diurnal variations of technical ability and swimming performance. Biological Rhythm Research, 47(3), 447461.

Ferrario, V. F., Tredici, G. and Crespi, V. (1980). Circadian rhythm in human nerve conduction velocity. Chronobiologia, 7(2), 205-209.

Forndran, A., Lastella, M., Roach, G. D., Halson, S. L. and Sargent, C. (2012). Training schedules in elite swimmers: No time to rest. Sleep of different populations. Adelaide: Australasian Chronobiology Society, 6-10. http://hdl.cqu.edu.au/10018/929372 
Fullagar, H. H., Skorski, S., Duffield, R., Hammes, D., Coutts, A.J. and Meyer, T. (2015). Sleep and athletic performance: the effects of sleep loss on exercise performance, and physiological and cognitive responses to exercise. Sports Medicine, 45(2), 161-186.

Garrido, N., Marinho, D.A., Reis, V. M., van den Tillaar, R., Costa, A. M., Silva, A.J. and Marques, M. C. (2010). Does combined dry land strength and aerobic training inhibit performance of young competitive swimmers? Journal of Sports Science and Medicine, 9(2), 300-310.

Gubin, D. G., Weinert, D., Rybina, S. V, Danilova, L. A., Solovieva, S. V., Durov, A. M., ... Ushakov, P. A. (2017). Activity, sleep and ambient light have a different impact on circadian blood pressure, heart rate and body temperature rhythms. Chronobiology International, 34(5), 632-649.

Halson, S. L. (2014). Sleep in elite athletes and nutritional interventions to enhance sleep. Sports Medicine, 44(1), 13-23.

Hill, D. W., Cureton, K. J., Collins, M. A. and Grisham, S. C. (1988). Diurnal variations in responses to exercise of morning types and evening types. Journal of Sports Medicine and Physical Fitness, 28(3), 213-219.

Hill, D. W. and Smith, J. C. (1991). Circadian rhythm in anaerobic power and capacity. Canadian Journal of Sport Science, 16, 30-32.

Hill, D. W. and Rowell, A. L. (1996). Significance of time to exhaustion during exercise at the velocity associated with VO2max. European Journal of Applied Physiology and Occupational Physiology, 72(4), 383-386.

Horne, J. A. and Ostberg, O. A. (1976). Self-assessment questionnaire to determine morningness-eveningness in human circadian rhythms. International Journal of Chronobiology, 4, 97-110 
Leeder, J., Glaister, M., Pizzoferro, K., Dawson, J. and Pedlar, C. (2012). Sleep duration and quality in elite athletes measured using wristwatch actigraphy. Journal of Sports Sciences, 30(6), 541-545.

Lemyre, P. N., Roberts, G. C. and Stray-Gundersen, J. (2007). Motivation, overtraining, and burnout: Can self-determined motivation predict overtraining and burnout in elite athletes? European Journal of Sport Science, 7(2), 115-126.

Lericollais, R., Gauthier, A., Bessot, N., Sesboue, B. and Davenne, D. (2006). Time-ofday effects on fatigue during a sustained anaerobic test in well-trained cyclists.

Chronobiology International, 26, 1622-1635.

Lubans, D. R., Morgan, P., Callister, R., Plotnikoff, R. C., Eather, N., Riley, N. and Smith, C. J. (2011). Test-retest reliability of a battery of field-based health-related fitness measures for adolescents. Journal of Sports Sciences, 29(7), 685-693.

Marshall, G. J. and Turner, A. N. (2016). The importance of sleep for athletic performance. Strength and Conditioning Journal, 38(1), 61-67.

Martin, A., Carpentier, A., Guissard, N., van Hoecke, J., and Duchateau, J. (1999). Effect of time of day on force variation in a human muscle. Muscle and Nerve, 22(10), $1380-1387$.

McNair, D. M., Lorr, M. and Droppleman, L. F. (1981). Profile of Mood States. San Diego, CA: Educational and Industrial Testing Services.

Morgan, K., David, B. and Gascoigne, C. (2007). Sleep diary. Clinical Sleep Research Unit, Loughborough University, United Kingdom.

Potdevin, F. J., Alberty, M. E., Chevutschi, A., Pelayo, P. and Sidney, M.C. (2011). Effects of a 6-week plyometric training program on performances in pubescent swimmers. Journal of Strength and Conditioning Research, 25(1), 80-86. 
Rae, D. E., Stephenson, K. J. and Roden, L. C. (2015). Factors to consider when assessing diurnal variation in sports performance: the influence of chronotype and habitual training time-of-day. European Journal of Applied Physiology, 115(6), 13391349.

Reilly, T. and Marshall, S. (1991).Circadian rhythms in power output on a swim bench. Journal of Swimming Research, 7, 11-13.

Reilly, T. and Down, A. (1992). Investigation of circadian rhythms in anaerobic power and capacity of the legs. Journal of Sports Medicine and Physical Fitness, 32, 343-347. Reilly, T. and Edwards, B. (2007). Altered sleep-wake cycles and physical performance in athletes. Physiology and Behaviour, 90(2), 274-284.

Reilly, T. and Waterhouse, J. (2009). Chronobiology and Exercise. Medicina Sportiva, $13,54-60$

Sargent, C., Halson, S. and Roach, G. D. (2014). Sleep or swim? Early-morning training severely restricts the amount of sleep obtained by elite swimmers. European Journal of Sport Science, 14(sup1), S310-S315.

Shephard, R. J. (1984). Sleep, biorhythms and human performance. Sports Medicine, $1(1), 11-37$.

Short, M. A., Gradisar, M., Lack, L. C, Wright, H. R. and Dohnt, H. (2013). The sleep patterns and well-being of Australian adolescents. Journal of Adolescence, 36(1), 103110.

Souissi, N., Bessot, N., Chamari, K., Gauthier, A., Sesbouee, B. and Davenne, D. (2007). Effect of time of day on aerobic contribution to the 30-s wingate test performance. Chronobiology International, 24, 739-748. 
Souissi, N., Souissi, M., Souissi, H., Chamari, K., Tabka, Z., Dogui, M. and Davenne, D. (2008). Effect of time of day and partial sleep deprivation on short-term, high-power output. Chronobiology International, 25(6), 1062-76.

Souissi, H. A., Chaouachi, K., Chamari, M., Dogui, M., Amri, M. and Souissi, N. (2010). Time of-day effects on short-term exercise performances in 10-11-years-old boys. Paediatric Exercise Science, 22, 613-623.

Spiegel, K., Tasali, E., Penev, P. and van Cauter, E. (2004). Brief communication: Sleep curtailment in healthy young men is associated with decreased leptin levels elevated ghrelin levels and increased hunger and appetite. Annals of Internal Medicine, 141, 846850.

Temfemo, A., Hugues, J., Chardon, K., Mandenque, S. H. and Ahmaidi, S. (2009). Relationship between vertical jumping performance and anthropometric characteristics during growth in boys and girls. European Journal of Paediatrics, 168(4), 457-464. Thompson, K. G., MacLaren, D. P., Lees, A. and Atkinson, G. (2002). Accuracy of pacing during breaststroke swimming using a novel pacing device, the Aquapace. Journal of Sports Sciences, 20(7), 537-546.

Thun, E., Bjorvatn, B., Flo, E., Harris, A. and Pallesen S. (2015). Sleep, circadian rhythms, and athletic performance. Sleep Medicine Reviews, 23, 1-9.

Vgontzas, A. N, Zoumakis, E., Bixler, E. O., Lin, H. M., Follett, A., Kales, A.

Chrousos, G. P. (2004). Adverse effects of modest sleep restriction on sleepiness, performance, and inflammatory cytokines. Journal of Clinical Endocrinology and Metabolism, 89, 2119-2126.

Waterhouse, J., Atkinson, G., Edwards, B. and Reilly, T. (2007). The role of a short post-lunch nap in improving cognitive, motor, and sprint performance in participants with partial sleep deprivation. Journal of Sports Sciences, 25(14), 1557-1566. 
Weissgerber, T. L., Mills, N. M, Winham, S. J. and Garovic, V. D. (2015). Beyond bar and line graphs: time for a new data presentation paradigm. PLOS Biology, 13(4), e1002128.

Weston, M., Hibbs, A. E., Thompson, K. G. and Spears, I. R. (2015). Isolated core training improves sprint performance in national-level junior swimmers. International Journal of Sports Physiology and Performance, 10(2), 204-210. 


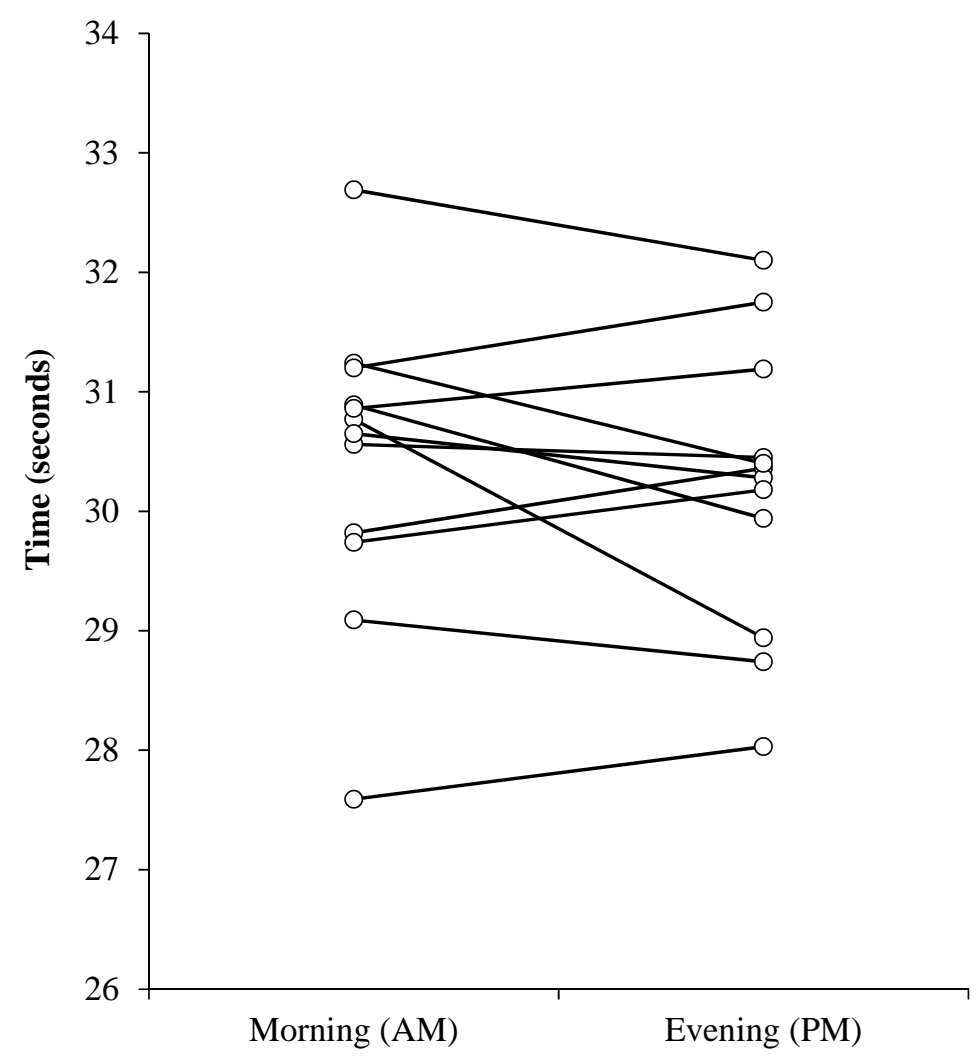

Figure 1. Paired data for individual times (s) in the morning and evening for 50m freestyle, $n$ = 12. Morning (05:30-06:30); evening (17:30-18:30). 


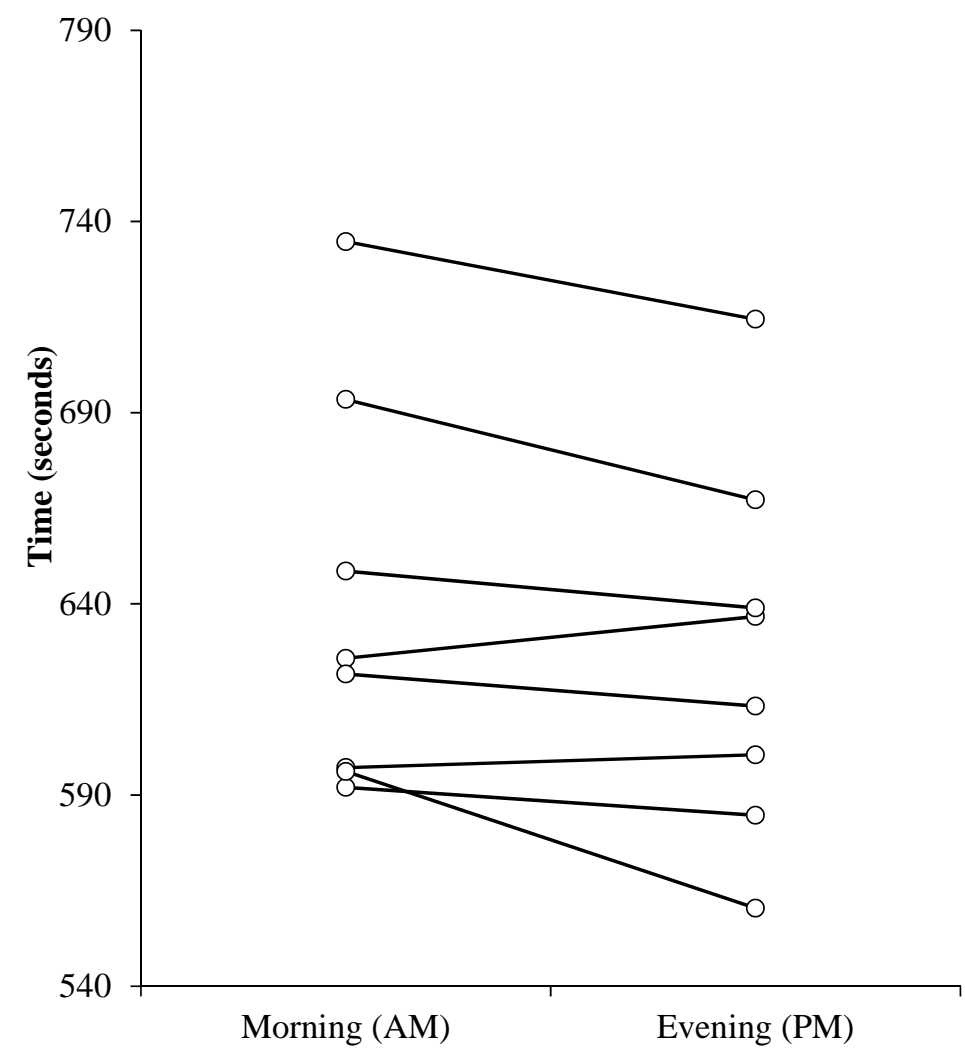

Figure 2. Paired data for individual times (s) in the morning and evening for $800 \mathrm{~m}$ freestyle, $\mathrm{n}=8$. Morning (05:30-06:30); evening (17:30-18:30). 


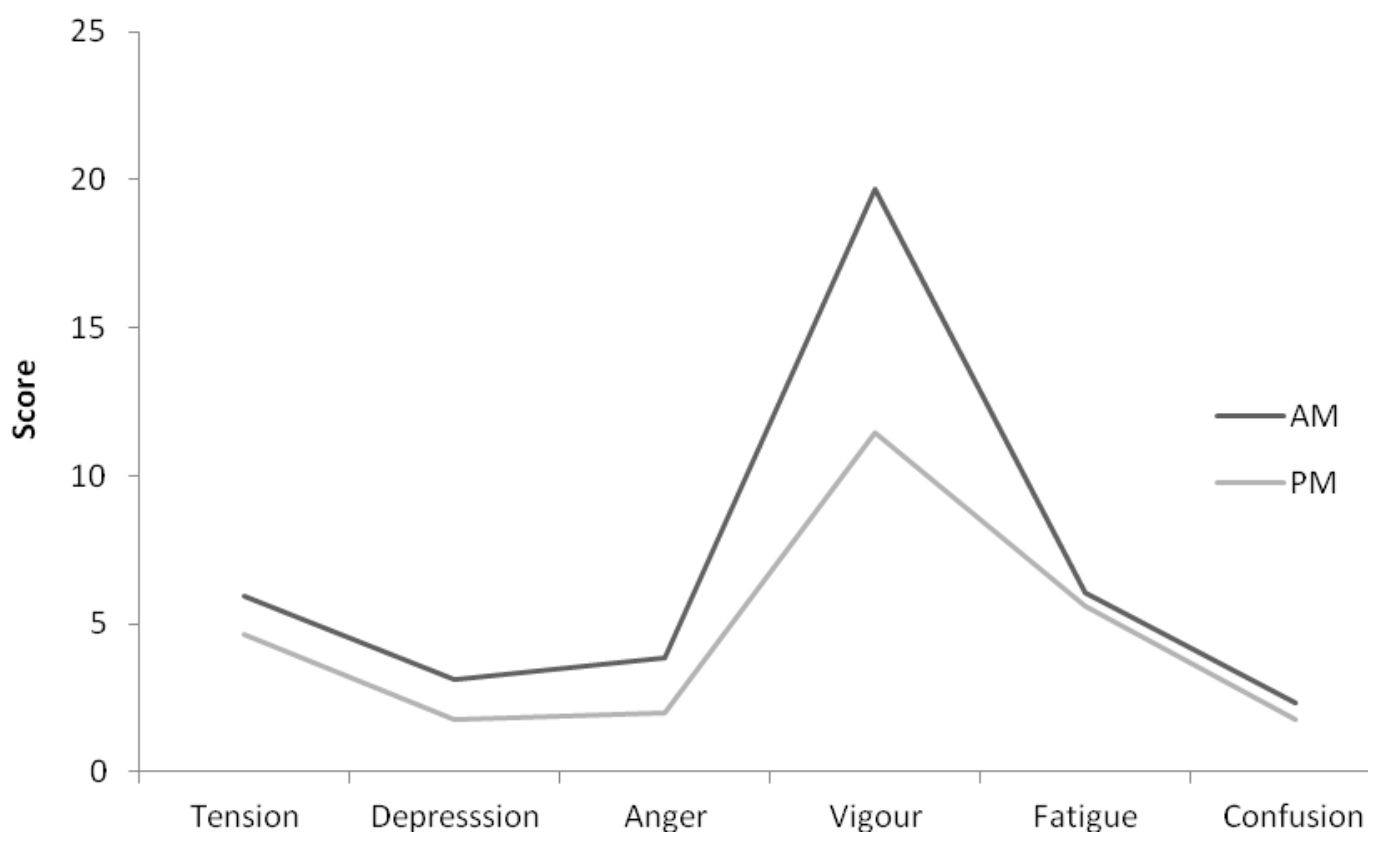

Figure 3. POMs variables measured in the morning and evening. Values are calculated means $(n=12)$. Error bars removed for clarity. 


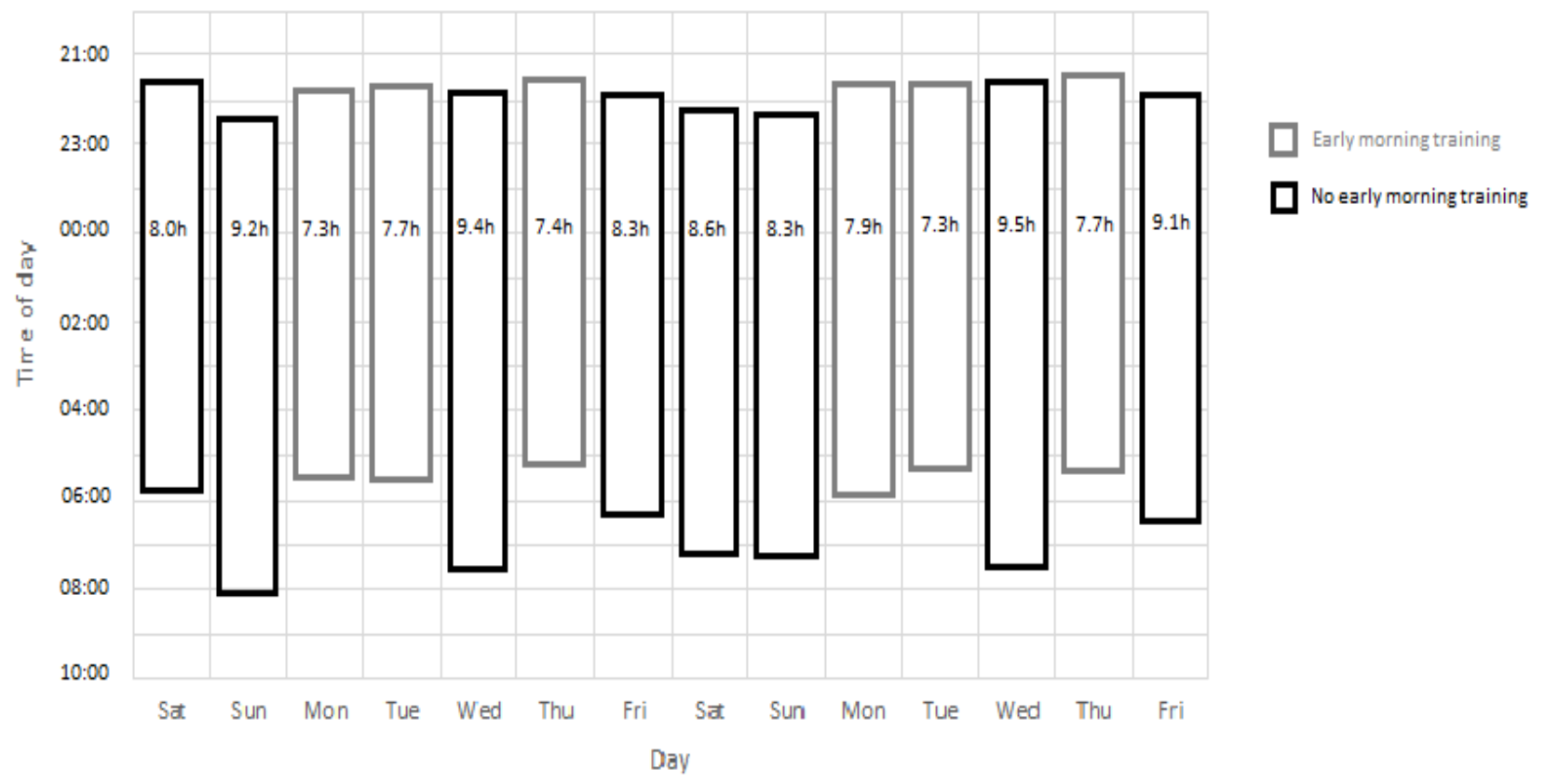

Figure 4. Schematic of average self-reported sleep patterns over a 14 day period. 
Table 1

Characteristics of swimmers (mean $\pm \mathrm{SD}$ )

\section{Chronological age (years) $\quad$ Weight (kg) Height $(\mathrm{cm})$}

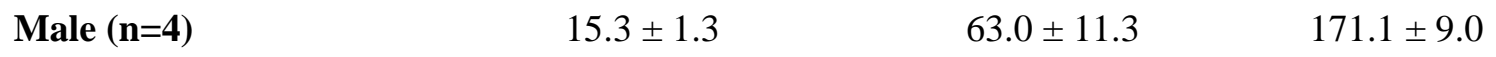

Female (n=8)

$14.6 \pm 2.4$

$57.8 \pm 8.3$

$165.2 \pm 4.4$

All $(n=12)$

$14.8 \pm 2.1$

$59.5 \pm 9.2$

$167.2 \pm 6.6$ 
Table 2

Physical parameters measured in the morning and evening

\begin{tabular}{lllll}
\hline Variable & AM & PM & P value & Effect size \\
\hline HG strength (kg) & $26.9 \pm 6.4$ & $29.7 \pm 7.0^{*}$ & 0.007 & 0.61 \\
Back and leg strength $(\mathbf{k g})$ & $91.4 \pm 28.1^{*}$ & $84.0 \pm 28.4$ & 0.013 & -0.37 \\
CMJ (cm) & $27.6 \pm 3.6$ & $27.9 \pm 5.6$ & 0.756 & 0.08
\end{tabular}

All values are means $( \pm \mathrm{SD}) .{ }^{*}$ indicates a significantly higher value $(p<0.05) . \quad \mathrm{HG}=$ handgrip ; CMJ = countermovement jump, $\mathrm{n}=12$. A negative effect size indicates a lower score in the morning. 